\title{
Descriptive review and comparison of clinical outcomes of AFAP patients
}

\author{
Heidi McCoy*, Wendy Kohlmann, Deborah W Neklason, Randall W Burt, Ken M Boucher \\ From 14th Annual Meeting of the Collaborative Group of the Americas on Inherited Colorectal Cancer \\ Dallas, TX, USA. 12-13 October 2010
}

\section{Objective}

This study aimed to examine the colonic polyp phenotype, the surgical outcomes, and the reasons for colectomy in individuals with Attenuated Familial Adenomatous Polyposis (AFAP).

\section{Methods}

Colonoscopy and colectomy medical records were obtained for 197 individuals with a known genetic mutation in the region of the $A P C$ gene causative of AFAP.

\section{Results}

The number of adenomas was highly variable for both individuals being screened by colonoscopy and those having had a colectomy. The probability of an AFAP patient in this cohort having a colectomy is only $20 \%$ at age 40 , however, after this age, the probability climbs dramatically. The average age of colectomy is 52 years. By age 70 , the cumulative probability of having a colectomy is approximately $80 \%$ in this AFAP population. When the population was broken into 5 equal sized birth cohorts (Figure1), we see a trend whereby colectomies are being performed at younger ages in the most recent cohorts $(\mathrm{p}=0.0001)$. The major reason for colectomy is a high number or polyps (Figure 1).

\section{Discussion}

Colectomy appears to becoming more common in patients with AFAP and is being recommended at younger ages. A greater number of colectomies were performed in the 1990s which coincided with the identification of the APC gene mutation in this family. Subtotal colectomy with ileorectal anastomosis (IRA) is the most common type of colectomy, though $23 \%$ still had

\footnotetext{
* Correspondence: hmccoy@myriad.com

Departments of Medicine, Human Genetics, and Oncological Sciences, University of Utah, Salt Lake City, Utah, USA
}

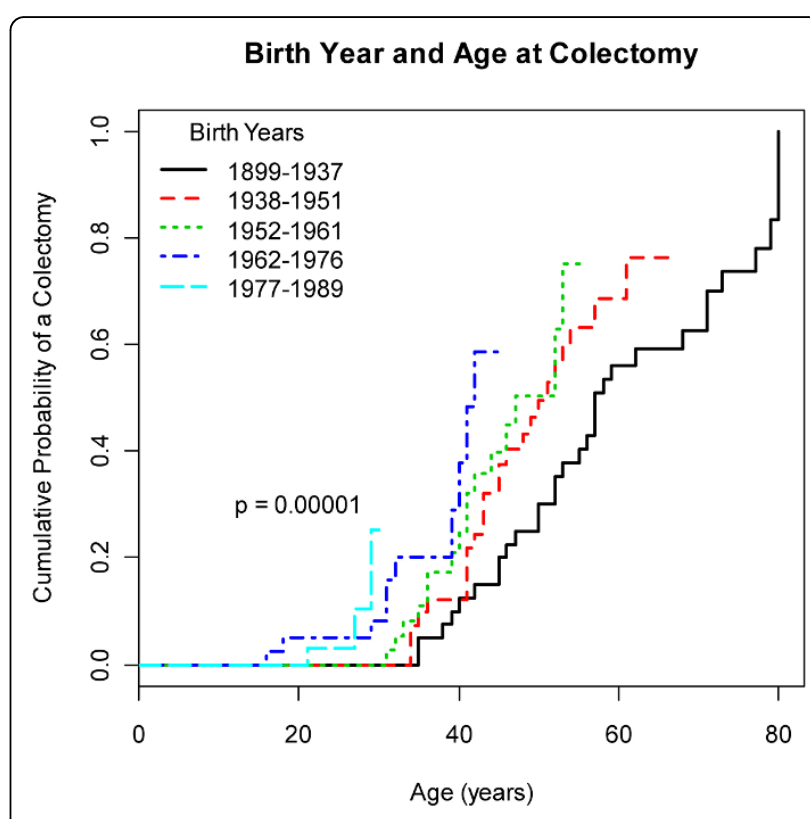

Figure 1 Age versus cumulative probability of having a colectomy by birth year. Individuals were divided into five nearly equal cohorts based on birth year.

proctocolectomies with ileoanal anastomosis. Cancer risk did not necessarily correlate with polyp number as 7 individuals with fewer than 20 polyps developed cancer. In the end several factors should be considered in developing a management plan for individuals with AFAP, including lifestyle, polyp number, comorbidities, adherence to screening and patient attitudes.

Published: 10 March 2011

doi:10.1186/1897-4287-9-S1-P25

Cite this article as: McCoy et al: Descriptive review and comparison of clinical outcomes of AFAP patients. Hereditary Cancer in Clinical Practice 2011 9(Suppl 1):P25.

\section{C)

(c) 2011 McCoy et al; licensee BioMed Central Ltd. This is an open access article distributed under the terms of the Creative Commons Attribution License (http://creativecommons.org/licenses/by/2.0), which permits unrestricted use, distribution, and reproduction in any medium, provided the original work is properly cited. 